\title{
Sá de Miranda, trovador e poeta
}

\author{
Márcia Arruda Franco \\ Universidade de São Paulo
}

\begin{abstract}
Os momos, os saraus de Portugal, tão falados no mundo, onde são idos? $\mathrm{E}$ as graças temperadas do seu sal?

Dos motes o primor e altos sentidos, os ditos delicados cortesãos, qu'é deles? Quem lhes dá somente ouvidos? ${ }^{1}$
\end{abstract}

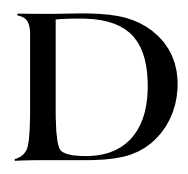

urante o século XV, em Castela e em Portugal, floresceu, sob a hegemonia do idioma poético castelhano, uma poesia dita palaciana. ${ }^{2}$ Em Portugal, no Cancioneiro Geral de Garcia de Resende, impresso em 1516, mas voltado para a poesia do século anterior e também contemporânea, são pela primeira vez impressas as trovas de Bernardim Ribeiro e do doutor Sá de Miranda, grandes amigos nos saraus manuelinos. ${ }^{3}$

${ }^{1}$ Estabeleço o vocábulo seraos para saraus e não para serões neste passo da Carta a Dom Fernando de Meneses, em resposta do que lhe escreveu de Sevilha, ver em MIRANDA, 1977, 104-5, o texto estabelecido por Lapa.

${ }^{2}$ Sobre a poesia palaciana ibérica, José de Sousa Machado comenta: "O Cancionero General de Hernan de Castillo, impresso em 1511, publicando as poesias dos fidalgos espanhóis, impressionou vivamente os poetas da côrte faustosa de D. Manuel e animou Garcia de Rezende a compilar os versos dos nossos trovadores que floresceram nos reinados de D. Afonso V, D. João II e D. Manuel." (MACHADO, 1928,38)". "Sá de Miranda começou, imitando os poetas do Cancioneiro General, glosando, em castelhano, os motes ou cantigas de Jorge de Manrique e de Garcia Sanchez; e nunca abandonou as formas tradicionais de redondilha, antes e depois de conhecer e aceitar a escola italiana, e de introduzir em Portugal o verso endecassílabo." (MACHADO, 1928, 39).

${ }^{3}$ A superioridade dos versos mirandinos no panorama desta coletânea é ponto pacífico, como, por exemplo, neste trecho de José de Sousa Machado: "O Cancioneiro Geral, de Rezende, impresso em 1516, publica treze poesias do Doutor Francisco Sá de Miranda. Seus versos, à maneira dos trovadores da época (quasi todos de 
Sá de Miranda nasceu provavelmente em 1487 e morreu em 1558. Saber com alguma exatidão o ano de nascimento de um escritor quinhentista é um feito notável, pois não sabemos quando nasceram autores como Gil Vicente e Camões. Até pouco tempo, o ano de nascimento de Sá de Miranda era desconhecido, e podia ter sido entre 1481 e 1495, por conta da informação vaga dada na sua vida anônima, publicada no século XVII, no conjunto de paratextos que abre a segunda edição das suas poesias, em $1614 .{ }^{4}$ Segundo a biografia seiscentista, o poeta nascera em um dia afortunado, quando começou o reinado de Dom Manuel I, em 1495, mas logo se julgou que o poeta era mais velho e que talvez tivesse nascido no dia que subiu ao trono Dom João II, em 1481. Gerado pela vontade do biógrafo anônimo seiscentista de enaltecer o nascimento do poeta, muitos livros, artigos, catálogos de bibliotecas ainda hoje mantém o equívoco, apesar de já há mais de uma década se saber a partir de um documento do Vaticano, publicado em 1991, que o poeta em 1509 contava 22 anos, e, portanto, ou nasceu por volta de 1487; trata-se de sua primeira súplica papal, ao papa Júlio II. ${ }^{5}$

O Chartularium Universitatis Portugalensis, ${ }^{6}$ coleção até agora com 15 volumes, reúne documentos do Vaticano sobre letrados e clérigos

boa linhagem, mais destros na espada que na pena, mas superiores à maioria dos fidalgos, que era quasi anafalbeta) já revelam o caracter do homem e a vivacidade e cultura do seu espírito; e a publicação entre as poesias dos melhores trovadores, denuncia o lisongeiro conceito e bom acolhimento que o moço poeta havia conquistado nos salões da côrte." (MACHADO, 1928,38). Sobre a amizade dos dois trovadores ver aqui editados os Diálogos poéticos com Leonor de Mascarenhas, ver também sobre as éclogas de ambos, assim como a sextina e algumas cantigas e vilancetes em torno do tema "imigo de si", os capítulos pertinentes do meu livro de 2005.

${ }^{4}$ Trata-se da segunda edição das poesias de Sá de Miranda, listada na bibliografia abaixo.

${ }^{5}$ Uma tradução deste documento, feita por Sebastião Tavares de Pinho, estará em breve disponível, no no de Floema, Caderno de Teoria e História Literária, da UESB-DELL, Vitória da Conquista, dedicado a Sá de Miranda e organizado por mim.

${ }^{6}$ Ver os volumes pertinentes do Chartularium Universitatis Portugalensis, (1501-1510), Lisboa, INIC, 1991, Vol.X; (1511-1520), Lisboa, JNICT, 1993, Vol.XI; (1521-1525), Lisboa, JNICT, 1995, Vol.XII; (1526-1529),Lisboa, Fundação para a Ciência e a Tecnologia, 1999,Vol.XIII. 
portugueses, cuja publicação foi iniciada em 1966, tendo os volumes referentes ao século XVI começado a sair em 1991. Nesta súplica referida, frei Sá de Miranda pede um benefício eclesiástico, a reitoria ou priorado da Igreja de São Julião do Mouronho. Nos próximos anos, buscará novos e maiores benefícios nas Dioceses de Coimbra e Braga, a fim de custear os seus estudos em Roma, onde teria se doutorado em cânones. ${ }^{7}$

No Cancioneiro Geral de Garcia de Resende, o trovador já era intitulado Doutor Sá de Miranda, porque também era doutor em decretos, provavelmente pelos Estudos Gerais portugueses com sede em Lisboa nesse momento. Sá de Miranda foi professor universitário em Lisboa antes de ir para a Itália do Renascimento, subsidiado pela estrutura eclesiástica, que funcionava como um órgão de fomento da cultura, fornecendo espécies de bolsas de estudo, através de priorados e reitorias paroquiais.

No renascimento, a cultura letrada se difunde primeiro nos círculos eclesiásticos investidos de uma função pedagógica, o que beneficia a escrita de uma poesia ao divino, próxima ao canto litúrgico e à prece, sendo central, como era, a prática da religiosidade na sociedade quinhentista. É nesse contexto que devem ser lidas as trovas à nossa senhora e às canções à virgem de Sá de Miranda.

Certamente foi em Itália que o clérigo trovador tentou os seus primeiros decassílabos, começou a escrever uma comédia, e não uma farsa, conforme a escola peninsular: ${ }^{8}$ a tradição trovadoresca ibérica, que tinha raízes galego-portuguesas, provençais, francesas e castelhanas. O trovador tenta a nova poética, centrada no princípio da imitatio, a partir de um hibridismo, sem descartar nenhuma tradição. De certo, a medida nova é tentada em sonetos, canções e elegias, mas os gêneros novos, como a carta e a écloga, e também a sextina foram escritos em redondilha maior, no metro peninsular.

A poesia palaciana em relação às cantigas galego-portuguesas, destinadas ao canto, apresenta uma perda da componente musical em favor de uma produção voltada para a leitura, ${ }^{9}$ mas nem tanto. Sendo áulica, era praticada de viva voz nos serões do paço; a sociedade de corte subsumia-se, por assim dizer, em várias cortes menores, como a de príncipes, princesas, senhoras nobres, grandes e pequenos senhores,

\footnotetext{
${ }^{7}$ FRANCO, 2005, p. 29-43.

${ }^{8}$ Ver EARLE, 2000.

${ }^{9}$ OSORIO, 1993, p. 97.
} 
sendo a sua condição, naturalmente, o palácio ou a casa senhorial. Nestes saraus, que se davam não apenas no serão do paço, o convívio com as damas propiciava o cultivo de uma poesia voltada para os sucessos ou as derrotas do amor, sendo este conceitualizado, conforme a releitura cristã das poéticas clássicas, característica do humanismo cristão lusíada, nos três registros, baixo, fino, alto, este último, o amor consagrado a Deus através do voto de castidade, desdobrava-se ainda nas relações entre a poesia e o cotidiano cristão quinhentista.

Alguns trovadores mantêm o costume galego-português de forjar a perspectiva feminina, escrevendo em nome de algumas damas reais da corte manuelina. Sá de Miranda também compôs do ponto de vista feminino, o cantar velho "Sola me dexaste", e outro, em diálogo, cantar de moças ao adufe, "Naquela serra", e ainda o cantar de moças, "Menina fermosa". A poesia mirandina recolhida no Cancioneiro de Resende mostra-se muito densa para a trivialidade do salão, sendo que o poeta não deixou nunca de freqüentar com suas trovas as recolhas quinhentistas e seiscentistas, sobretudo com os cantares escritos na perspectiva feminina.

Uma dama da corte de D. Maria, Leonor de Mascarenhas, a marquesa de Pescara portuguesa, segundo Sá de Miranda, compõe duas sextilhas em resposta a ele e a Bernardim Ribeiro, em dois diálogos poéticos ao gosto provençal, "Ua cousa cuidava eu" e "Vi sinais: o mal é grande", que não foram editados no Cancioneiro de Resende em 1516. Quem os salva do esquecimento é o próprio Sá de Miranda reunindo-os em sua obra, quando as ofertou ao príncipe no início dos anos 1550 (Manuscrito D). ${ }^{10}$ Os diálogos poéticos dessa dama da corte manuelina com os dois maiores trovadores do Cancioneiro de Resende foram editados em 1595, ${ }^{11}$ mas não em 1614. Embora fora do Cancioneiro Geral é bem dentro desta prática palaciana do poético que estes diálogos foram forjados (ver no 51 e n⿳052 da edição de1885).

Entre o trovadorismo medieval e a poesia palaciana, transição em parte documentada pelo Cancioneiro de Baena, que traz algumas composições ainda em galego-português, houve não só uma progressiva

\footnotetext{
${ }^{10}$ Manuscrito D porque pertenceu a Ferdinand Denis e se encontra hoje em Paris, na BNP, do qual possuo cópia. Há uma nota do poeta: "polo dela que é cousa rara pus aqui isto por que se veja que Portugal teve a sua marquesa de Pescara". Ver MIRANDA, 1885, n⿳ำ 50 e no 51 , p.40.

${ }^{11}$ Trata-se da edição príncipe de 1595 . Ver bibliografia.
} 
aristocratização do poeta e da poesia, mas também uma redefinição de gêneros e formas. Alguns autores como Le Gentil querem derivar esta renovação formal da influência que a poesia cortês francesa do norte teria exercido sobre a poesia palaciana da península.

A adoção de formas derivadas (Cantiga, Vilancete, Mote, Glosa, Trovas) de modelos franceses resultou num esquecimento das raízes provençais do trovadorismo ibérico, mas nunca das raízes galegas. Por exemplo, a cantiga de mal-maridada de Sá de Miranda, Dona Bela. No Cancioneirito, reunião de trovas editada ao fim da edição de Ferrara da História de Mneina e moça, o tema da mal-maridada é bem desenvolvido não só no trecho mirandino, mostrando-nos a vitalidade de que gozou este tema medieval no século XVI português.

A tradição poética peninsular, fortemente oralizada, está presente além de em ajudas de caráter áulico, nos diálogos e nas disputas da série de cantigas e cantares velhos. Por outro lado, de dentro da tradição ibérica, a poesia da Provença persistiu em formas como a Esparsa, o Diálogo poético, a Canção. Algumas formas provençais continuam cultivadas pelos poetas palacianos ibéricos: a esparsa e o diálogo poético, por exemplo, são ecos do trovadorismo occitânico nos serões manuelinos, flores de uma árvore trovadoresca. Por outro lado, a origem provençal das formas, para os renascentistas peninsulares, nem sempre é clara, como no caso da sextina, do soneto e da canção quinhentistas, compostos à maneira italiana.

O esquecimento da matriz provençal, na tradição castelhana, evidencia-se, por exemplo, no fato de o Marquês de Santillana, na primeira metade do século XV, apenas ter ouvido falar de Arnaut Daniel; sabe que ele cultivou sonetos e a terça rima antes de Dante, mas nunca pôde ler as suas composições, porque não dispunha de nenhuma edição manuscrita da poesia da Provença, na primeira metade do século XV. Ao expor a hierarquia da prática poética - Sublime, Medíocre e Ínfimo - revela o seu desconhecimento das fontes provençais e bolonhesas, as primeiras a usarem o idioma vulgar em formas poéticas, isto é, que compunham obras pertencentes ao grau do meio ou medíocre:

Mediocre usaron aquellos que en vulgar escriuieron, asy commo Guido Januncello boloñés e Arnaldo Daniel proençal. E commo quier que destos yo no he visto obra alguna; pero quieren algunos auer ellos sido los primeros que escriuieron tercio rimo e aun sonetos en romance. ${ }^{12}$

${ }^{12}$ SANTILLANA, 1989, Vol.2, p.214. 
Como observa Jorge Alves Osório, ${ }^{13}$ as diversas manifestações do trovadorismo peninsular (catalão, galego-português, castelhano) e europeu (provençal e bolonhês) e a poesia italiana são apresentadas por Santillana, na carta ao condestável D. Pedro de Portugal, com a mesma estratégia argumentativa com que são apresentadas as letras antigas, valorizando-se, assim, a poesia em língua vulgar e o papel da leitura na formação do poeta palaciano. Passando por cima de um desconhecimento pessoal dos textos da poesia Provençal, o Marquês, a partir do elogio feito por Dante ao "miglior fabro", coloca o trovadorismo occitânico na base da poesia italiana do dolce stil nuovo, ressaltando a precedência dos provençais e bolonheses no cultivo de algumas formas. Por nunca ter podido ler as trovas occitânicas, a forma sextina nem é mencionada na carta do Marquês.

$\mathrm{Na}$ cena castelhana, o esquecimento da raiz provençal consuma-se quase um século adiante de Santillana, no discurso de Juan del Encina, que considera, sem delongas, a poesia italiana como origem do trovadorismo espanhol. Para o tratadista, a etimologia do vocábulo trovar é italiana, "trovare quer dizer hallar", isto é, encontrar ou inventar "sentencias e razones e consonantes e pies de cierta medida". ${ }^{14}$ A origem italiana da poesia palaciana espanhola não é posta em questão: "Assi que concluyamos luego: el trobar aver cobrado sus fuerças en Italia e de alli esparzidolas por nuestra España adonde creo que ya florecen mas que en otra ninguna parte". ${ }^{15}$

Isto não quer dizer que no início do século XVI um poeta como Sá de Miranda não tivesse consciência da relação entre a poesia galegoportuguesa e a provençal, e da relação desta última com a poesia de Petrarca, como se pode ver neste famoso passo da sua carta elegíaca a D. Fernando de Meneses:

Despois co'a melhor lei, entrou mais lume, suspirou-se melhor, veo outra gente de que Petrarca fez tam rico ordume.

\footnotetext{
${ }^{13}$ OSORIO, 1993,p. 95.

${ }^{14}$.MENENDEZ PELAYO, 1946, Vol.1, Apêndice V, p.515

${ }^{15}$ Ibidem, p. 516.
} 
Eu digo os Proençais, de que ao presente inda rimas ouvimos, que entoaram as musas delicadas altamente. ${ }^{16}$

Sá de Miranda, que podia perceber a influência dos provençais em Petrarca, não sabia que Arnaut Daniel inventou a sextina. Como Santillana, Sá de Miranda reconhece o fato de a poesia provençal estar tanto na base da poesia italiana (do dolce stil nuovo e de Petrarca) como na base da tradição trovadoresca peninsular, pois "ainda se sente o som das brandas rimas que entoarão". ${ }^{17}$

As formas cultivadas pelos provençais como a canção, a sextina e o soneto, porém, não remetem, nas obras dos poetas portugueses do Renascimento, para a matriz provençal e sim para a italiana ou petraquista ou stilnovista. Quando, na primeira metade de quinhentos, os poetas portugueses cultivam a sextina, promovem um hibridismo entre a tradição peninsular e a italiana. A esse respeito é clara a rubrica mirandina: "Sextina à italiana no nosso medida". ${ }^{18}$

Os sonetos quinhentistas, ao contrário dos sonetos de Sá de Miranda, logo ganham uma circulação palaciana, e oral, ou seja, integram o circuito da vida cortês, ao lado das trovas de salão lírico-amorosas e satíricas. São muitos os poetas quinhentistas que alcançam a expressão do ritmo italiano na forma soneto, introduzida por Sá de Miranda, que, entretanto, debate-se entre duas tradições, buscando uma outra queda para o soneto através das linhas emaranhadas do bibridismo rítmico. ${ }^{19} \mathrm{~A}$ reforma mirandina começa a introduzir as formas e os gêneros da poesia italiana em medida velha. Ela não é uma tentativa de suprimir o bibridismo, que persiste até na pesquisa rítmica do decassílabo.

O soneto mirandino tem uma queda bem reflexiva que explora o lado culto da forma nova curta. Difunde-se, em torno do poeta, o emprego do soneto como prólogos que abrem quer as remessas de suas poesias reunidas para serem ofertadas ao príncipe como as remessas de e respostas a contemporâneos que copiaram a sua própria obra sob um soneto-prólogo, ofertando-a a Sá de Miranda, para que a lesse e desse a

\footnotetext{
${ }^{16}$ Carta a Dom Fernando de Meneses, in: LAPA, 1977, p.102.

${ }^{17}$ MIRANDA, 1885, p.253.

${ }^{18}$ MIRANDA, 1885, p.58, no 74, nota.

${ }^{19}$ MIRANDA, 1885 e PIMPÃO, 1972.
} 
sua opinião sobre ela, o que o poeta fez algumas vezes em sonetos como naqueles em que responde a Dom Manuel de Portugal e a Pero de Andrade Caminha, de modo que a forma adquire um lugar central na circulação da nova poesia e na difusão dos novos princípios criativos. É assim que muitos sonetos são recriações de mitologemas como o lindo conto de Leandro e Hero, ou a morte de Policena, ou a relação entre Cupido e Vênus.

Se o soneto lírico amoroso circula no sarau, sobretudo em língua catelhana, glosando a tópica do mal amor que leva à morte e à loucura, aproximando o conflito do amante do conflito do poeta ao se debater entre tantas tradições poéticas ao escrever o seu poema, o tema mitológico, por sua vez, também é praticado em redondilha como na esparsa "À vossa bula de amor", dando mostras de como a inovação absorveu e foi absorvida pela tradição peninsular. Pode-se dizer que houve um sincretismo entre a nova e a velha poesia. O hibridismo poético está presente na poesia peninsular desde a primeira metade do século XV. O longo caminho (séculos XV e XVI) que levou à modernização da poesia tradicional ibérica, através da adoção dos temas e das formas italianas e clássicas, trouxe para a criação poética um espaço de experiencialismo, responsável pela convivência, na poesia palaciana e na do renascimento, de traços medievais e modernos.

A poesia palaciana portuguesa, no ocaso da Idade Média, caracteriza-se por ser um cadinho de tendências poéticas. Dante e Petrarca exercem influência no nível temático, os trovadorismos francês, provençal e galego-português, no formal, mas a língua utilizada é quase sempre a castelhana.

Houve, na primeira metade do século XV, a tentativa do Marquês de Santillana de suprimir o hibridismo, ao fazer alguns sonetos "al itálico modo". Esta tentativa de assimilação formal do soneto italiano não gorou. Menéndez Y Pelayo considera os sonetos de Santillana a primeira tentativa malograda de captação do ritmo do decassílabo italiano na península ibérica, antecedendo de um século a reforma de Boscán e Garcilaso.

Muito se ganha ao se considerar a tentativa do Marquês como marca do grau da influência dos poetas do primeiro renascimento italiano na cena poética quatrocentista ibérica. Por exemplo, o soneto "Quando yo só delante aquella donna" é um soneto do dolce stil nuovo renovado, escrito em castelhano na primeira metade do século XV, em que a deificação da amada serve a uma redefinição cristã da humanidade: 
Quando yo só delante aquella donna,

A cuyo mando me sojudgó Amor,

Cuydo ser uno de los que en Tabor

Vieron la gran claror que se raçona,

Ó quella sea fija de Latona,

Segund su aspetto é grande resplandor:

Asy que punto yo non hé vigor

De mirar fixo su deal persona.

El su grato fablar dulçe, amoroso,

Es una maravilla çiertamente,

É modo nuevo en humanidat:

El andar suyo es con tal reposo,

Honesto é manso, é su continente,

Que, libre, vivo en captividad. ${ }^{20}$

A tentativa de captação da forma peregrina do Marquês foi isolada e só será retomada um século depois por seu parente direto Garcilaso de la Vega, por Boscán, por Sá de Miranda e por Dom Manuel de Portugal, na primeira metade de quinhentos. Sá de Miranda possuía um manuscrito das obras de Garcilaso de la Vega, que o seu amigo, o Senhor de Bastos, António Pereira Marramaque, lhe ofertara, como se pode ler nas versões da dedicatória de Nemoroso, écloga escrita em homenagem ao grande Laso. $^{21}$ E desta vez a forma será bem lograda, seja por Garcilaso e por seu amigo Boscán, seja pela escola mirandina ou pela camoniana. A noção de poeta como cultor das letras antigas, porém, já penetrara a poesia palaciana, em Castela, desde a primeira metade do século XV.

Osório nos explica que:

Em boa medida é com o aumento da componente culta na utilização crescente da língua vulgar, precisamente no momento em que se enfatiza a afirmação da consciência da dignidade das línguas nacionais

\footnotetext{
${ }^{20}$ A rubrica do soneto XIV reza: "En este catorçéssimo soneto el actor muestra que, quando es delante aquella su señora, le paresçe que es en el monte Tabor, en el qual Nuestro Señor aparesçió á los tres descípulos suyos; é por quanto la estoria es muy vulgar, non cura de la escrevir." (SANTILLANA, 1989, v.1, p. 315).

${ }^{21}$ FRANCO, 2005, p.137-148.
} 
face ao latim, que se verifica a divulgação dos termos poeta e poesia nas línguas vulgares, aplicados à pratica também em vernáculo. ${ }^{22}$

É só no século XVI, porém, que o português passa a ser amplamente usado como idioma poético, único capaz de expressar a identidade lusíada. A vertente culta e reflexiva da poesia palaciana (cantigas, vilancetes, esparsas e diálogos - composições trovadorescas de cariz humanista) apresenta-se por um hibridismo poético com características formais do trovadorismo (provençal, galego-português, ibérico e francês) e temáticas da poesia do primeiro renascimento italiano, no que tange à dimensão autobiográfica, na imitação da vida, presente na redescoberta do ponto de vista individual, através do cultivo do tema amoroso na poesia em língua vulgar. O trovadorismo palaciano toma como idioma principal o castelhano, mas também usa a língua portuguesa cada vez mais. Quando as formas novas, italianas e clássicas foram amplamente difundidas e praticadas, os poetas portugueses nunca deixaram de lado o cultivo das trovas palacianas. O que se verifica é uma contaminação de códigos poéticos: através dos códigos poéticos do trovadorismo palaciano a imitação é relida, sendo adaptada ao sistema de mote e glosa.

O hibridismo poético caracteriza os primórdios da aventura de introdução das formas italianas na poesia escrita em língua portuguesa, na virada entre os séculos XV e XVI. Isto é, ao introduzirem as formas e os gêneros italianos (o soneto, a sextina, a canção e também aquelas mais reflexivas e clássicas como a, ode a elegia, a carta moral e a écloga pastoril) os primeiros quinhentistas continuaram a lançar mão do hibridismo poético praticado na tradição cancioneiril, que há um século se humanizava na corte central do cenário ibérico, isto é, em Castela, quer quando trovavam em castelhano, quer quando em português.

Em Portugal, na passagem do século XV para o XVI, a poesia se humanizou passo a passo: primeiro houve uma reflexão temática de modo petrarquista, mas de jeito ibérico (o ciclo do "imigo de si"), o voltar-se do poeta sobre a sua própria subjetividade, tema coado naturalmente da lírica amatória castelhana, que se pode chamar de um bibridismo temático-formal, formas tradicionais remetendo a temas petrarquistas. Alguns vilancetes, cantigas e glosas do Cancioneiro de Resende, como as de Sá de Miranda e Bernardim Ribeiro, trazem um questionamento do

${ }^{22}$ OSÓRIO, 1993, p.97. 
sujeito característico dos homens modernos, que centram a virtude na vontade ou a loucura na perda da vontade. Em seguida, houve uma tentativa de mistura formal das tradições (bibridismo formal): uma aceitação do gênero, da forma, mas não da métrica, como se verifica na prática inicial da sextina, da carta e da écloga. Este último passo (o da aceitação da métrica) será dado pela escola mirandina. A aventura de introdução das formas clássicas e italianas se estende por todo o século XVI, culminando com a tragédia Castro (de António Ferreira,) e Os Lusíadas, publicados na segunda metade do século XVI.

O sucesso da reforma poética (levada adiante pela escola nova) a mudança de trovador a poeta - não se verifica por um repúdio da tradição trovadoresca, malgrado António Ferreira, e não se limita a uma questão de métrica. Ao contrário, mesmo quando o ritmo italiano é domado pelos autores portugueses, estes continuam a cultivar os ritmos $\mathrm{e}$ as formas tradicionais. As formas e os gêneros cancioneiris prestam-se tanto a temas circunstanciais da vida áulica quanto a temas humanistas.

Em suma, rejeitar o império do vulgo (uma concepção de poeta fora da noção de estudo humanista) não se confunde com o desprezo da tradição poética em medida velha. O magistério mirandino consiste em despertar os poetas para a infinidade de temas (fora da cuita amorosa) sugeridos pelo renascimento das Letras e pela nova concepção do fazer poético: a emulação dos modelos antigos e italianos através do processo criativo da imitatio. ${ }^{23} \mathrm{O}$ poeta ainda se preocupa em resguardar a parte sã da tradição trovadoresca, lançando mão dos recursos formais trovadorescos e da longa tradição galego-portuguesa para promover o desengano de uma lírica só de queixume amoroso, sendo consciente, conforme os trovadores provençais, mas seguindo os autores antigos, ${ }^{24}$

${ }^{23}$ Ler a carta dedicatória de Sá de Miranda a Dom Duarte na História crítica da literatura portuguesa, humanismo e renascimento, org. de José Augusto Cardoso Bernardes, e o meu artigo, "Duas versões da dedicatória de Os Estrangeiros". Convergência Lusiada, Revista do Real Gabinete Português de Leitura do Rio de Janeiro, 2005.

${ }^{24}$ Saulo Neiva em sua obra citada pondera : "L'épître en vers apparaît ainsi comme un discours d'exaltation du loisir - à en croire, par exemple, les vers suivants, qu'António Ferreira a adressés à Sá de Miranda : " Chamarte-ei sempre bem aventurado... " (NEIVA, 1999,p.198). "Cicéron souhaite ainsi affirmer la dimension morale de l'otium, en associant sa pratique à la vie de ces personnages 
de que a leitura e escrita da poesia e a prática da filosofia trazem um olor que desvanece o tédio.

O poeta acabou casando-se com Dona Briolanja de Azevedo, de nobre estirpe, um pouco antes de 1530, com cerca de 43 anos. Apesar da carreira eclesiástica, sugerida pelo defeito de nascimento (pois Sá de Miranda era filho de cônego com mulher solteira, como o seu ilustre irmão Men de Sá), nunca tomou ordens maiores, podendo desta forma livremente se casar, usando abertamente o hábito de cavaleiro da ordem de Cristo. Depois de casado, Dom João III definitivamente beneficiou-lhe com a Comenda das Duas Igrejas, em Braga, objeto maior das súplicas de Sá de Miranda, segundo documentos publicados no Chartularium....

Na última década de sua vida, o poeta se muda para a Quinta da Tapada, entre os rios Cávado e Homem, morada onde perde o filho na tardia cruzada do Monte Condessa, em 1553, e a mulher dois anos depois, tendo por fim falecido em data incerta depois de maio de $1558 .{ }^{25}$

Justifica-se assim uma edição de Sá de Miranda ${ }^{26}$ que dê relevo à sua produção trovadoresca, seguindo uma indicação do próprio poetatrovador, quando reúne grande parte da sua poesia, nos primeiros anos da última década de sua vida, para ofertá-las ao príncipe Dom João, neto de Dom Manuel I, enviando, na primeira remessa, as trovas de salão manuelinas, seguidas dos sonetos, finalizando com trovas à virgem e canção petrarquista também à virgem, como se o seu cancioneiro fosse iniciado pelas trovas do tempo do Venturoso e terminado com uma canção italiana em louvor da virgem. As famosas cartas e écloga mirandinas, do tempo joanino, em virtude das quais entrou para a historiografia literária como o poeta filósofo, introdutor das formas e do metro italiano na

de renom et ne soulignant combien cette habitude leur permet d'exercer avec plénitude leur condition d'hommes libres, maîtres d'eux-mêmes. Car, retranchés sur leurs propres terres, ces hommes eurent le même dessein que les rois: ne manquer de rien, n'obéir à personne et jouir de la liberté qui est essentiellement vivre comme l'on veut.. (Ibidem, p. 200)

${ }^{25}$ MACHADO, 1928.

${ }^{26}$ Esclareço que duas edições distintas de Sá de Miranda foram por mim preparadas: uma, panorâmica, a ser publicada em Portugal em 2008, e outra intitulada O Cancioneiro de Sá de Miranda, que ainda aguarda uma editora. O presente artigo é parte da introdução desta segunda edição. 
poesia portuguesa de quinhentos, são apenas parte da sua produção. Não que achemos o poeta oficial menor do que o trovador, cabe ressaltar, porém, que valorizar a herança trovadoresca na base da renovação formal sugerida pela poesia italiana e do renascimento resultou na constante trovadoresca da história da poesia portuguesa quinhentista, quando, à maneira ibérica, é dada a volta à nova poesia, através da prática do hibridismo, ao longo de todo o período clássico da poesia portuguesa, mas em especial durante o século XVI, quando as mesmas formas da poesia trovadoresca dão margem a um desenvolvimento letrado característico da releitura que o renascimento português fez da antigüidade clássica e do primeiro renascimento italiano. Como inovador, o poeta-trovador lança uma moda, mas não prescreve a antiga, gerando uma norma de conduta, o hibridismo poético, que dá ouvidos à moda peninsular trovadoresca, buscando os laços perdidos do trovadorismo provençal, busca que se exemplifica com Rodrigues Lobo, no seu suposto Prólogo às Rimas de Camões, de 1595, já ciente de que a sextina foi inventada na Provença.

Entretanto o lugar das redondilhas mudaria do pórtico para o final das edições quinhentistas como produções menos perfeitas do verso, pois a noção de acento rítmico não era regrada como na nova poesia do renascimento, subordinada ao ritmo do verso.

Sá de Miranda que viveu a mudança nunca totalmente levada a cabo de trovador a poeta entendia o entroncamento trovadoresco da península ibérica nas tradições occitânicas e bolonhesas, apesar de não saber que a sextina era invenção de Arnaut Daniel, tanto que praticou, antes de um petrarquismo amoroso, um stilnovismo renovado, preferindo as imagens de Dante, De Cino da Pistoia e de outros poetas do século XIII para descrever o enamoramento, ${ }^{27}$ usando o modelo da canção de Petrarca no seu louvor à Virgem.

${ }^{27}$ PINA MARTINS, 1988. p.149-162. 


\section{Bibliografia}

EARLE, T. F. "Sá de Miranda's Roman Comedy".In: LOWE, Cultural lines between Portugal and Italy in the Renaissance. Oxford: Oxford University Press, 2000.

FRANCO, Marcia Arruda Sá de Miranda, poeta do século de ouro. Coimbra: Angelus Novus, 2005

LE GENTIL, Pierre. La poésie lyrique espagnole et portugaise a la fin du Moyen Age. Rennes: Plihon, 1949/ 1952. 2 vols.

LAPA, Rodrigues, org. Obras Completas de Sá de Miranda. Lisboa: Sá da Costa, 1976/1977, 2 vols.

MACHADO, José de Sousa. Opoeta do Neiva. Notícias biográficas e genealógicas recolhidas e compostas por -. Braga: Livraria Cruz, 1928.

MARTINS, José Vitorino de Pina. "Sá de Miranda e a recepção no século XVI de um dolce stil nuovo renovado". Separata do volume o Humanismo Português (1500-1600), I, 1985. Lisboa: Academia das Ciências de Lisboa, 1988. p.149-162.

MENÉNDEZ PELAYO, M . Historia de las Ideas Estéticas en España. Santander: Aldus, 1946. Vol. 1, Apendice V, p.515.

MIRANDA. Francisco de Sá de Poesias. Edição feita sobre cinco manuscritos inéditos e todas as edições impressas, acompanhadas de um estudo sobre o poeta, variantes, notas, glossário e um retrato por Carolina Michaëlis de Vasconcelos. Halle: Max Niemeyer, 1885; e Poesias de Sá de Miranda. Edição Fac-similada. Lisboa, INCM, 1989

NEIVA, Saulo. Au nom du loisir et de l'amitié. Rhetoric et morale dans l'épitre en vers en langue portugaise au XVIe siècle. Paris: Centre Cultural Calouste Gulbenkian, 1999.

As obras do celebrado lusitano, o doutor Frãcisco de Sá de Mirãda. Collegidas por Manoel de Lyra, 1595

As obras do Doctor Francisco de Saa de Miranda. Agora de novo impressas com a Relação de sua calidade, e vida. Lisboa: Vicente Alvarez, 1614

OSORIO, Jorge Alves. "Trovador e poeta do século XIII ao século XVI - algumas considerações". Línguas e Literaturas, Revista da Faculdade de Letras do Porto, Porto, II série, vol. X, p. 93-108, 1993.

PIMPÃO, Álvaro Júlio da Costa. "O soneto O sol é grande" In:-. Escritos diversos. Coimbra: Coimbra, 1972.

SANTILlanA, Marqués de. Poesías Completas. Edición de Manuel Durán. Madrid: Editorial Castalia, 1989. 2 vols. 


\section{Resumo}

Escrito para introduzir a minha edição do Cancioneiro de Sá de Miranda - ainda inédita e sem editor -, este artigo pretende refletir sobre as relações entre o trovadorismo palaciano praticado por Sá de Miranda e seus contemporâneos e os diversos trovadorismos anteriores, sobretudo oprovençal e o galego-português. Também é colocada a questão da renovação poética implícita na prática híbrida do trovadorismo palaciano, como uma etapa prévia à renovação formal propiciada pela difusão do novo código renascentista, centrado no princípio criativo da imitação.

\section{Abstract}

Written to introduce mine edition of Sá de Miranda's Cancioneiro, still not published and without publisher, this text means to think about the relationship between the poetry practiced in the early XVI th century and that practiced in the Middle Ages, in the south of France and in Spain and Portugal. Also it is pointed out that the innovation set by the diffusion of renaissance poetic principles, based on the practice of imitation, was already present in the hybrid practice of Sá de Miranda and his mates. 